\title{
BMJ Determinants of workplace injury Open among Thai Cohort Study participants
}

\author{
Janneke Berecki-Gisolf, ${ }^{1}$ Benjawan Tawatsupa, ${ }^{2}$ Roderick McClure, ${ }^{1}$ \\ Sam-ang Seubsman, ${ }^{2,3}$ Adrian Sleigh, ${ }^{2}$ The Thai Cohort Study Team
}

To cite: Berecki-Gisolf $\mathrm{J}$, Tawatsupa B, McClure R, et al. Determinants of workplace injury among Thai Cohort Study participants. BMJ Open 2013;3:e003079. doi:10.1136/bmjopen-2013003079

- Prepublication history for this paper is available online. To view these files please visit the journal online (http://dx.doi.org/10.1136/ bmjopen-2013-003079).

Received 18 April 2013 Revised 6 June 2013 Accepted 17 June 2013
${ }^{1}$ Monash Injury Research Institute, Monash University, Melbourne, Victoria, Australia ${ }^{2}$ National Centre for Epidemiology and Population Health, Australian National University, Canberra, Australian Capital Territory, Australia

${ }^{3}$ School of Human Ecology, Sukhothai Thammathirat Open University, Nonthaburi, Thailand

\section{Correspondence to} Dr Janneke Berecki-Gisolf; janneke.berecki-gisolf@ monash.edu

\section{ABSTRACT}

Objectives: To explore individual determinants of workplace injury among Thai workers.

Design: Cross-sectional analysis of a large national cohort.

Setting: Thailand.

Participants: Thai Cohort Study participants who responded to the 2009 follow-up survey were included if they reported doing paid work or being selfemployed $(n=51751)$.

Outcome measures: Self-reported injury incidence over the past 12 months was calculated. Multivariate logistic regression models were used to test associations between individual determinants and self-reported workplace injury.

Results: Workplace injuries were reported by 1317 study participants (2.5\%); the incidence was 34 (95\% $\mathrm{Cl} 32$ to 36)/1000 worker-years for men, and 18 (1720 ) for women. Among men working $\geq 41 \mathrm{~h}$ and earning $<10000$ Baht, the injury rate was four times higher compared with men working $<11 \mathrm{~h}$ and earning $\geq 20001$ Baht; differences in injury rates were less pronounced in women. Multivariate modelling showed that working $\geq 49 \mathrm{~h} /$ week $(23 \%)$ and working for $\leq 10000$ Bath/month (37\%) were associated with workplace injury. The increase in injury risk with increased working hours did not exceed the risk expected from increased exposure.

Conclusions: Reductions in occupational injury rates could be achieved by limiting working hours to 48/ week. Particularly for Thai low wage earners and those with longer workdays, there is a need for effective injury preventive programmes.

\section{INTRODUCTION}

Thailand is a newly industrialised country. The transition to a modern consumer economy is accompanied by a shift in birth and death rates, disease patterns and injury risks. ${ }^{1}$ Until recently, $46 \%$ of employed Thais were working in the agricultural sector, but the proportion of industrial workers is rapidly increasing. ${ }^{2}$ Occupational health and safety is being increasingly recognised in Thailand as an important component of population health and well-being. At the transitioning stage,

\section{ARTICLE SUMMARY}

Article focus

- Research informing occupational health and safety policy in Thailand has been largely at the employer, the community and the primary healthcare level.

- The aim of the present study was to investigate individual determinants of workplace injury among Thai workers participating in a large national Thai Cohort Study (TCS).

- The objectives were to determine the impact of working hours and level of income on workplace injury risk.

Key messages

- Of the study participants who were doing paid work or were self-employed, $3.4 \%$ of the men and $1.8 \%$ of the women reported a workplace injury that occurred over the past 12 months.

- Those working more than $48 \mathrm{~h} /$ week and working for a low income, and particularly self-employed workers working for a low income, were at increased risk.

- Part-time workers were at increased injury risk per hour worked, but their injury risk per worker-year was reduced compared with full-time workers.

Strengths and limitations of this study

- The strengths of this study are its large sample size and distribution of participants across Thai regions, urban and rural areas, occupations, formal and informal work and wage levels.

- A study limitation was the self-report nature of the data, which relies on accurate recall and reporting.

Thailand is facing both old and new occupational health problems: many traditional hazards in workplaces, such as silica, lead and unsafe work practice, still exist while new hazards related to changing working environments are emerging. ${ }^{2}$ An example is increasing levels of stress at work, which may trigger deterioration of workplace safety. Actions underway in Thailand to improve occupational health and safety include the implementation of an occupational health and safety surveillance system, a 'healthy workplace program' to promote safety, ${ }^{2}$ and a large-scale pilot 
programme integrating occupational and environmental health services into existing public health systems. ${ }^{3}$ Another area recently targeted in policy is pesticide poisoning among farmers.

While the role of individual-level risk factors such as working hours and resulting fatigue is not well studied in Thailand, there is evidence from other countries that extended work hours increase the risk of injury ${ }^{4}$ independent of industry and occupation. ${ }^{5}$ In Ethiopia, a developing country, working $\leq 48 \mathrm{~h} /$ week was found to be negatively associated with occupational injury in small-scale and medium-scale industries. ${ }^{6}$ The impact of working hours on workplace injury risk has not been investigated in the Thai context.

Individual-level determinants, such as working hours, are not specific to a workplace, industry or sector. Occupational injury risks arising from modifiable individual-level determinants can potentially be addressed in injury preventive measures across Thailand. Therefore, the aim of the present study was to investigate individual determinants of workplace injury among Thai workers participating in a large national Thai Cohort Study (TCS). In particular, this study will address the impact of working hours and level of income on workplace injury risk.

The research informing occupational health and safety policy in Thailand has been largely at the employer, the community and the primary healthcare level. Much of the occupational health and safety research has focused on formal employment, which accounts for only a third of the Thai workforce. ${ }^{7}$ Among Thais working in the non-formal sector, the safety of working conditions has deteriorated over recent years. ${ }^{8}$ This is especially so for chemical injuries among informal agricultural workers. Also, informal workers are more likely to work longer hours than formal workers and this would be expected to increase injury risks. Informal workers are therefore not excluded from this study: TCS participants who engaged in paid employment or were self-employed in 2009 are included.

\section{METHODS}

In this cross-sectional analysis of the TCS, self-reported workplace injury was determined among those respondents of the second survey (in 2009) who were doing paid work or self-employed. Although the first (2005) and second (2009) surveys contained detailed questions about injury, the 2009 survey questions were designed to fully capture traffic and non-traffic injury, also among those who had both a traffic and a non-traffic accident in the previous year. This analysis is therefore focused on the second survey only. Work status information is not derived from the 2005 survey because it is likely to have changed over the 4 years between the surveys.

\section{Study population and data collection}

The data were derived from the 2009 follow-up survey of the TCS, which is an ongoing community-based study of adult distance learning Sukhothai Thammathirat Open
University (STOU) students residing throughout the country. In 2005 the STOU student register listed about 200000 names and addresses: a baseline 20-page questionnaire was sent to each student and $87134(44 \%)$ replied. The 2005 baseline characteristics of cohort participants ${ }^{9}$ and comparisons with the population of Thailand ${ }^{1}{ }^{10}$ have been reported previously: the STOU cohort has a higher proportion of women than the general Thai population ( $54.7 \%$ vs $50.5 \%)$; more young adults $(51.5 \%$ vs $23.9 \%$ were aged between 21 and 30 years) and fewer people aged over 50 (2\% vs $24.7 \%) .{ }^{10}$ Study participants were also less likely to be married and more likely to have completed junior high school; geographically the main regions in Thailand are well represented in the STOU cohort. ${ }^{10}$

Overall the cohort represents well the geo-demographic, ethnic, occupational and socioeconomic status of the young-adult Thai population. This is because most Open University students already have established jobs and because of their work and family responsibilities and modest economic circumstances are unable to leave their locations to attend an on-campus university fulltime. However, they are better educated than the general Thai population and thus are able to respond to complex health questionnaires. In 2009, a follow-up survey was sent and 60569 (>70\%) participants replied: $55 \%$ were women and the median age was 34 years (range 19-92). Data scanning, verifying and correcting were conducted using Scandevet, a program developed by a research team from Khon Kaen University. Further data editing was completed using SQL and SPSS softwares.

\section{Ethical considerations}

Ethics approval was obtained from STOU Research and Development Institute (protocol 0522/10) and the Australian National University Human Research Ethics Committee (protocols 2004344 and 2009570). Informed written consent was obtained from all participants.

\section{Sample}

The sample inclusions and exclusions are shown in figure 1 . In the survey of 2009, study participants were asked "What is your current work status? (You can choose more than one option)" with possible answers: Doing paid work/Self-employed/Help family business but no wage/Doing unpaid work/Look after home (homemaker)/Student/Retired (do not work for income)/ Seeking work for the first time/Unemployed/Cannot work due to temporary sickness or disability/Cannot work due to permanent sickness or disability/Other. Those who indicated they were doing paid work and/or self-employed were included in this study. Participants were also asked to report "How many hours per week do you work in all paid jobs?" Those who did not provide this information were excluded. Inclusion was based entirely on response to the 2009 survey; responses to the 2005 survey were not considered. 


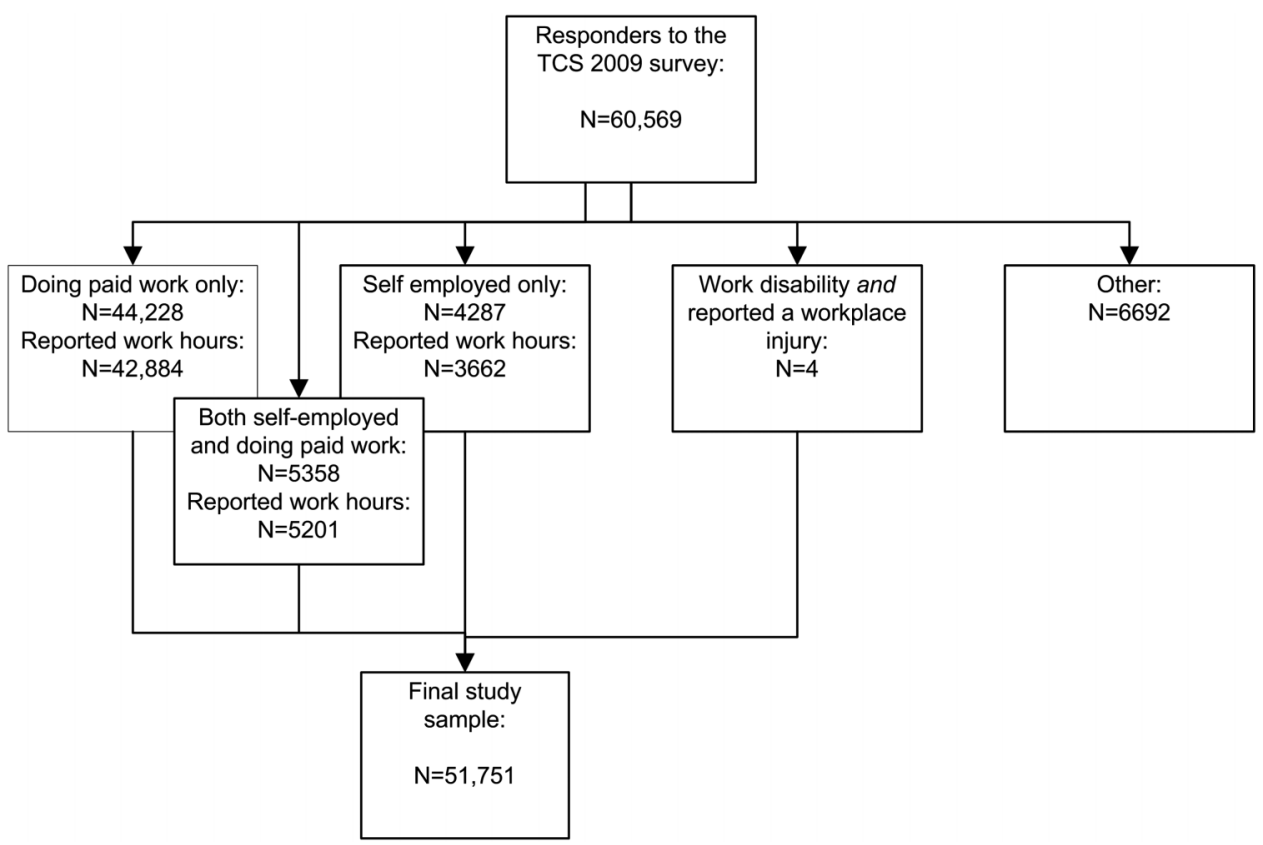

Figure 1 Inclusions and exclusions of study sample. Only those reporting work hours were included: 42884 were doing paid work only; 3662 were self-employed, 5201 were both self-employed and doing paid work and 4 reported a work disability as well as a recent workplace injury.

Participants who reported having had a workplace injury leading to limited activity, and who also indicated that they could not work due to a temporary or permanent sickness or disability, were included in the analyses. Their working hours (prior to injury) were imputed by the sample median. The final sample consists of 51751 participants.

\section{Workplace injury}

The core questions asked were: (1) "In the last 12 months how many times did you have a NON-TRAFFIC injury?" with possible answers never/one/two/three/four or more; (2) "What was the location at which your most serious non-traffic related injury occurred?" with possible answers home/sports facility/workplace (agricultural)/ workplace (non-agricultural)/other and (3) "When you experienced your most serious non-traffic related injury did you receive medical care?" with possible answers yes/no. Workplace injury was defined as non-traffic related injury that occurred in the workplace, agricultural or nonagricultural, and for which medical care was received. Non-traffic injuries that occurred outside the workplace were not considered in this study.

\section{Self-employment}

Self-employment was used as a proxy for informal employment. ${ }^{11}$ Study participants who indicated 'Self employed' in response to the question about current work status were therefore considered to be informally employed.

\section{Determinants of workplace injury}

The median number of working hours/week was 40 , IQR (10-48). The distribution was multimodal. There were three spikes in the distribution: $18 \%$ of participants reported working $8 \mathrm{~h}$ /week; $21 \%$ reported working $40 \mathrm{~h}$ and $11 \%$ reported working $48 \mathrm{~h}$. The working hours were therefore categorised as follows: $\leq 10,11-39,40$, $41-48$, and $\geq 49 \mathrm{~h} /$ week. The TCS survey of 2009 did not include questions about working in agriculture or farming, or about working multiple jobs.

The 2009 TCS survey included questions about marital status, area of residence, working hours, monthly personal wages and alcohol consumption.

\section{Analysis}

Analyses were performed in SAS V.9.2 (SAS Institute, Cary North Carolina, USA). To gain insight into risk factors for workplace injury, injury incidence was calculated per 1000 worker-years (self-reported workplace injury in the past year in the numerator and the 51751 study participants engaged in paid work in the denominator). To explore gender differences, for example, workplace injury incidence was calculated for men and women separately. However, possible gender differences could be attributed to men working more hours per year than women. To account for differences in work exposure duration, workplace injury incidence was also calculated per hours worked expressed per $1000000 \mathrm{~h}$. The results can be converted to American full-time equivalents (FTE): assuming a $40 \mathrm{~h}$ work week and 52 work weeks/year equates $2080 \mathrm{~h}$; to convert the injury rates to 100 FTE-years, they should be multiplied by a 
factor 0.2080 . The results of this study are presented per $1000000 \mathrm{~h}$ to avoid confusion about the 'standard' number of hours worked per year, which may differ substantially per country.

To calculate the workplace injury incidence per 1000 worker-years, the number of persons with a workplace injury sustained in the past 12 months was divided by the total number of workers, and multiplied by 1000 . To calculate the incidence per $1000000 \mathrm{~h}$ worked, the number of persons with a workplace injury was divided by the sum of weekly hours worked by all workers (multiplied by 52 to obtain the hours worked per year), and multiplied by 1000000 . CI for the incidence rates were calculated by first assuming injury occurrence to have a Poisson distribution, and finding its related CI. ${ }^{12}$

A multiple logistic regression model was used to test factors that were likely to be associated with workplace injuries. The model was gender-stratified. Covariates were individual-level work-related factors (income, hours of paid work and self-employment) and demographics that could confound the association between workrelated factors and risk of injury (age, gender, marital status, area of residence and alcohol intake).

The association between exposure variables and the outcome, that is, workplace injury for which medical help was sought, could be confounded by access to health services. The multivariate logistic regression model was therefore repeated for a modified outcome: workplace injury, regardless of medical help sought.

\section{RESULTS}

\section{Workplace injury}

Workplace injuries for which medical help was sought were reported by 1317 study participants $(2.5 \%) ; 3.4 \%$ of the men and $1.8 \%$ of the women reported a workplace injury. The types of injury are summarised in table 1 . The most commonly reported workplace injuries were cuts, bites or open wounds (35\%) and sprains, strains or dislocations $(33 \%)$. Bruising or superficial injury was more common among participants with injuries sustained in agricultural work; cuts, bites or open wounds also tended to be more common among agricultural work injuries.

The incidence of workplace injury was 34 (95\% CI 32 to 36) /1000 worker-years for men, and 18 (17-20) for women. The incidence per 1000 worker-years as well as the incidence per $1000000 \mathrm{~h}$ worked is summarised in table 2. Incidence was greatest in the age group 3039 years, men, participants who were never married, live in rural areas, are in the lowest wage category, work the most hours, are self-employed and regularly drink alcohol.

\section{Self-employment and workplace injury}

Self-employment was reported by $17 \%$ or workers. Compared with other paid workers, self-employed workers were more likely to work over $49 \mathrm{~h} /$ week $(30 \%$ vs $21 \%$ ). They were more likely to have a low income of $<7000$ Baht $(25 \%$ vs $11 \%)$, but they were also more likely to have a high income of $>30000$ Baht $(16 \%$ vs $9 \%)$. The injury incidence of workplace injury per worker-years, as well as per hours worked, was greater among the self-employed (table 2). This held true for low earners (self-employed workers had 30 (25-37) and other paid workers had 22 (19-25) injuries $/ 10^{6}$ worked hours) and for mid-range earners (17 (15-20) vs 12 (11-13)) but not for high earners (>30 000 Baht) who had $9(6-13)$ versus $9(7-11)$ injuries $/ 10^{6}$ worked hours for self-employed versus other workers, respectively.

\section{Determinants of workplace injury}

The high incidence of workplace injury among low earners was more pronounced among men than women

Table 1 Workplace injury types for agricultural and non-agricultural injuries for which medical care was sought*

\begin{tabular}{|c|c|c|c|c|c|c|c|}
\hline & \multicolumn{2}{|c|}{$\begin{array}{l}\text { Agricultural workplace } \\
\text { injury }(n=347)\end{array}$} & \multicolumn{2}{|c|}{$\begin{array}{l}\text { Non-agricultural } \\
\text { workplace injury } \\
(n=970)\end{array}$} & \multirow[b]{2}{*}{$\chi^{2}$} & \multirow[b]{2}{*}{ df } & \multirow[b]{2}{*}{ p Value } \\
\hline & $\mathbf{N}$ & $(\%)$ & $\mathbf{N}$ & (\%) & & & \\
\hline \multicolumn{8}{|l|}{ Nature of the injury } \\
\hline Fracture & 32 & (9) & 96 & $(10)$ & 0.1 & 1 & 0.7 \\
\hline Sprain, strain or dislocation & 127 & (37) & 313 & (32) & 2.2 & 1 & 0.1 \\
\hline Cut, bite or open wound & 136 & (39) & 324 & (33) & 3.8 & 1 & 0.05 \\
\hline Bruise or superficial injury & 109 & (31) & 234 & (24) & 7.0 & 1 & 0.008 \\
\hline Burn/scald & 19 & (5) & 47 & (5) & 0.2 & 1 & 0.6 \\
\hline Concussion & 61 & (18) & 137 & (14) & 2.4 & 1 & 0.1 \\
\hline Organ system (internal) injury & 42 & (12) & 104 & (11) & 0.5 & 1 & 0.5 \\
\hline Other & 41 & (12) & 130 & (13) & 0.6 & 1 & 0.5 \\
\hline \multicolumn{8}{|l|}{ Injury types reported } \\
\hline None & 5 & $(1)$ & 18 & $(2)$ & 7 & 2 & 0.03 \\
\hline One & 218 & (63) & 678 & (70) & & & \\
\hline Two or more & 124 & (36) & 274 & (28) & & & \\
\hline
\end{tabular}


Table 2 Incidence of workplace injury from the second Thai Cohort Study survey*

\begin{tabular}{|c|c|c|c|c|c|c|c|}
\hline \multirow[b]{2}{*}{ Variable } & \multirow[b]{2}{*}{ Paid workers } & \multirow[b]{2}{*}{ Hours worked } & \multirow{2}{*}{$\begin{array}{l}\text { Injured at the } \\
\text { workplace }\end{array}$} & \multicolumn{2}{|c|}{$\begin{array}{l}\text { Incidence } \\
\text { (events/1000 } \\
\text { workers years) }\end{array}$} & \multicolumn{2}{|c|}{$\begin{array}{l}\text { Incidence } \\
\text { (events } / 10^{6} \\
\text { hours worked) }\end{array}$} \\
\hline & & & & & $95 \% \mathrm{Cl}$ & & $95 \% \mathrm{Cl}$ \\
\hline \multicolumn{8}{|l|}{ Age (years) } \\
\hline$<30$ & 13466 & 484352 & 338 & 25 & 22 to 28 & 13 & 12 to 15 \\
\hline $30-39$ & 22609 & 818742 & 639 & 28 & 26 to 31 & 15 & 14 to 16 \\
\hline $40-49$ & 12392 & 430020 & 284 & 23 & 20 to 26 & 13 & 11 to 14 \\
\hline$\geq 50$ & 3284 & 105121 & 56 & 17 & 13 to 22 & 10 & 8 to 13 \\
\hline \multicolumn{8}{|l|}{ Gender } \\
\hline Women & 28428 & 976250 & 524 & 18 & 17 to 20 & 10 & 9 to 11 \\
\hline Men & 23323 & 861985 & 793 & 34 & 32 to 36 & 18 & 16 to 19 \\
\hline \multicolumn{8}{|l|}{ Marital status } \\
\hline First marriage & 24924 & 883648 & 570 & 23 & 21 to 25 & 12 & 11 to 13 \\
\hline Never married & 17229 & 619014 & 490 & 28 & 26 to 31 & 15 & 14 to 17 \\
\hline Other & 5182 & 184475 & 141 & 27 & 23 to 32 & 15 & 12 to 17 \\
\hline Missing data & 4416 & 151098 & 116 & 26 & 22 to 32 & 15 & 12 to 18 \\
\hline \multicolumn{8}{|l|}{ Area } \\
\hline Rural & 22104 & 773206 & 597 & 27 & 25 to 29 & 15 & 14 to 16 \\
\hline Urban & 29077 & 1044702 & 706 & 24 & 23 to 26 & 13 & 12 to 14 \\
\hline \multicolumn{8}{|c|}{ Monthly income (Baht) } \\
\hline$\leq 7000$ & 7005 & 226603 & 285 & 41 & 36 to 46 & 24 & 21 to 27 \\
\hline $7001-10000$ & 12168 & 418784 & 350 & 29 & 26 to 32 & 16 & 14 to 18 \\
\hline $10001-20000$ & 19595 & 711783 & 426 & 22 & 20 to 24 & 11 & 10 to 13 \\
\hline $20001-30000$ & 7660 & 278719 & 159 & 21 & 18 to 24 & 11 & 9 to 13 \\
\hline$\geq 30001$ & 5233 & 199328 & 94 & 18 & 15 to 22 & 9 & 7 to 11 \\
\hline \multicolumn{8}{|c|}{ Weekly hours of paid work } \\
\hline$\leq 10$ & 14561 & 116813 & 304 & 21 & 19 to 23 & 50 & 44 to 56 \\
\hline $11-39$ & 6360 & 155600 & 148 & 23 & 20 to 27 & 18 & 15 to 21 \\
\hline 40 & 10921 & 436840 & 240 & 22 & 19 to 25 & 11 & 9 to 12 \\
\hline $41-48$ & 8088 & 379064 & 224 & 28 & 24 to 32 & 11 & 10 to 13 \\
\hline$\geq 49$ & 11821 & 749918 & 401 & 34 & 31 to 37 & 10 & 9 to 11 \\
\hline \multicolumn{8}{|l|}{ Self-employment } \\
\hline Yes & 8863 & 311580 & 301 & 34 & 30 to 38 & 19 & 16 to 21 \\
\hline No & 42888 & 1526655 & 1016 & 24 & 22 to 25 & 13 & 12 to 14 \\
\hline \multicolumn{8}{|l|}{ Alcohol } \\
\hline None & 35149 & 1236917 & 755 & 21 & 20 to 23 & 12 & 11 to 13 \\
\hline 1-5/week & 7086 & 257715 & 236 & 33 & 29 to 38 & 18 & 15 to 20 \\
\hline 6 or more/week & 7407 & 275276 & 264 & 36 & 31 to 40 & 18 & 16 to 21 \\
\hline
\end{tabular}

*The most serious non-traffic injury that occurred in the past 12 months was included if it occurred in the workplace, and if medical care was received for the injury. To take differences in exposure duration into account, incidence was also reported per $1000000 \mathrm{~h}$ of paid work.

(figure 2). Among men working $\geq 41 \mathrm{~h}$ and earning $<10000 \mathrm{Baht}$, the injury rate was four times higher compared with men working $<11 \mathrm{~h}$ and earning $\geq 20001$ Baht; differences in injury rates were less pronounced in women (table 3). The association between weekly working hours and injury differed for injury incidence expressed per worker-years (figure 3, top) and incidence expressed per worked hours (figure 3, bottom). The incidence per worker-years increased with hours worked, whereas the incidence per worked hour is greatest in the group with the least hours worked per week.

The results of the multivariate logistic regression model stratified by sex show that working hours and income were independently associated with workplace injury (table 4). Working $\geq 49 \mathrm{~h} /$ week was associated with workplace injury in both men and women. Among both men and women earning a monthly personal income of $\leq 10000$ Baht was also associated with workplace injury. Among those earning $>10000 \mathrm{Baht} / \mathrm{month}$, increase in income was not associated with a further reduction in injury. In women but not in men, first marriage was negatively associated with workplace injury. In men but not in women, age above 50 years was negatively associated, and self-employment and alcohol consumption were positively associated with workplace injury.

The multivariate logistic regression was repeated for a modified outcome: workplace injury, regardless of medical help sought. Although this outcome may include very minor injuries, any potential confounding by access to health services is removed. Any workplace injury, regardless of whether medical help was sought, 


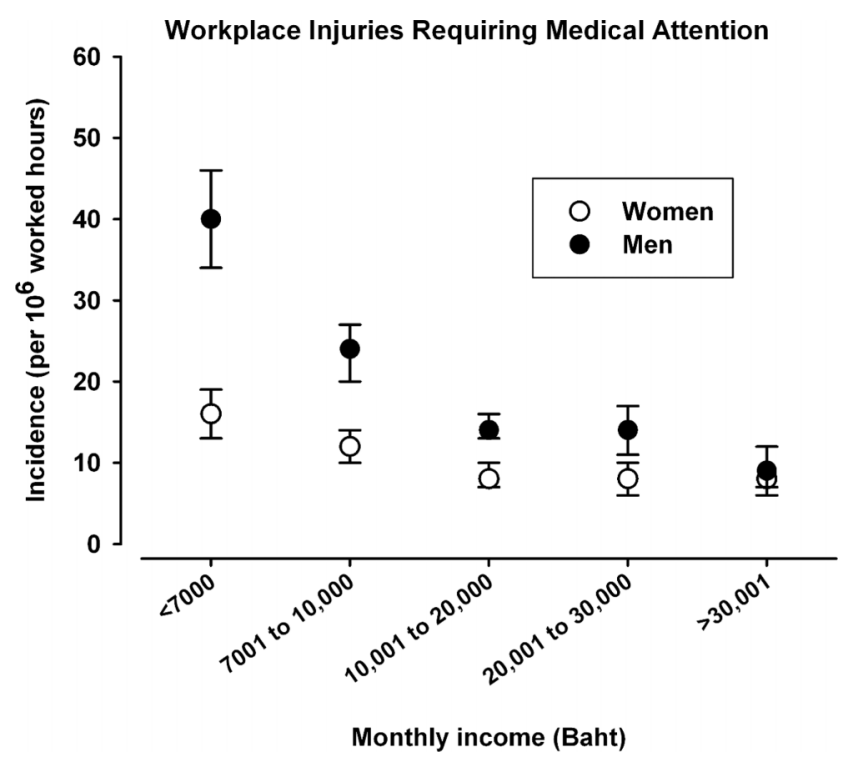

Figure 2 Incidence of workplace injury by monthly income.

was reported by 6275 participants; $14 \%$ of men and $11 \%$ of women reported a workplace injury. Women reported having had any workplace injury 5.8 times as often as they reported a workplace injury for which medical help was sought, among men this was 4.1 times. The pattern of association between exposure variables and outcome was similar to that shown in table 4 , with one noteworthy exception. For women, increasing age was statistically significantly associated with less workplace injury (age 30-39: OR 0.9 (95\% CI 0.8 to 1.0 ); age 40-49: 0.7 (0.6 to 0.8 ); age $\geq 50$ : 0.6 (0.4 to 0.8 ); reference ages $<30$ years).
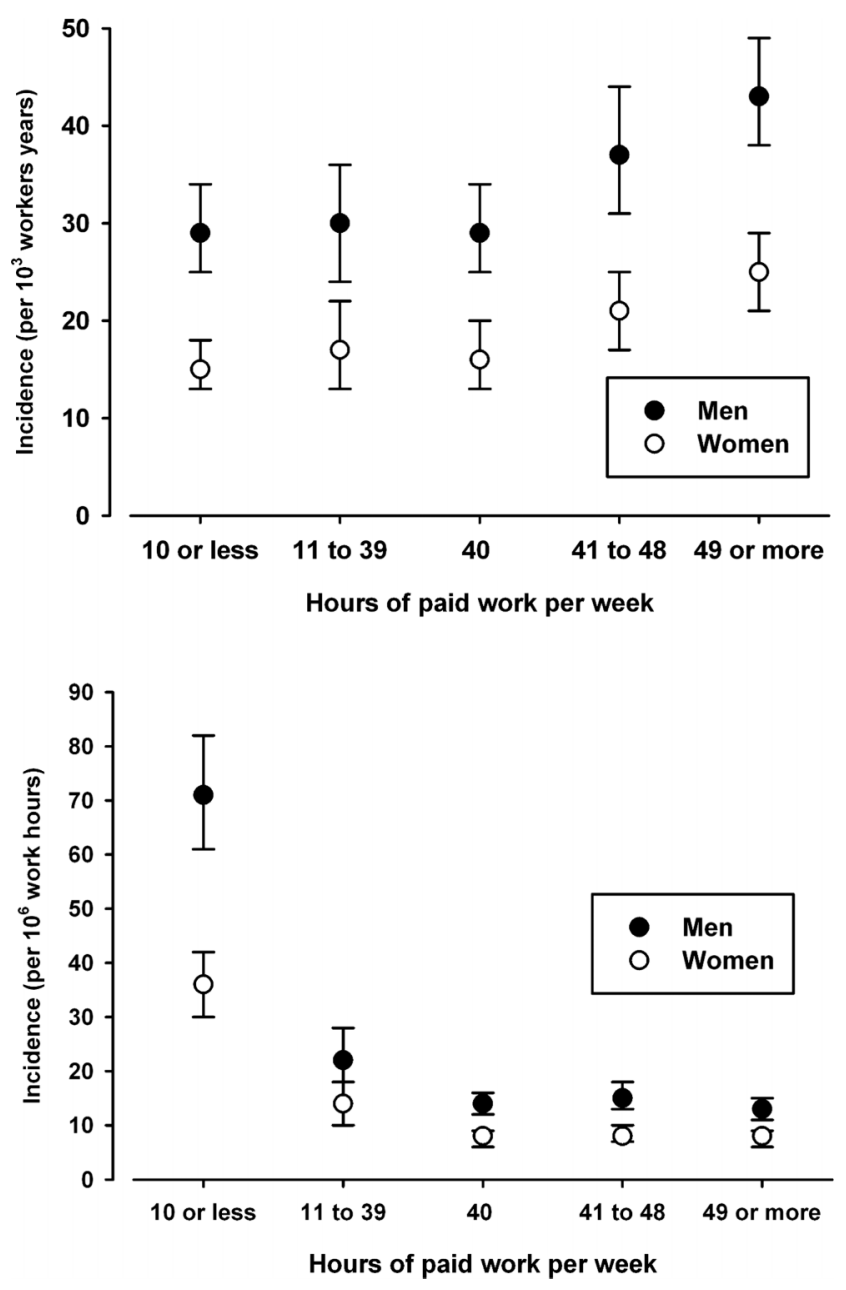

Figure 3 Incidence of workplace injury by weekly working hours.

Table 3 Incidence of workplace injury (injuries/1000 worker-years) by hours worked and monthly income, for men and women

\begin{tabular}{l|lll}
\hline & Hours of paid work/week & & \\
\hline $\begin{array}{l}\text { Men } \\
\text { Monthly income }\end{array}$ & $<11 \mathrm{~h}$ & $11-40 \mathrm{~h}$ & $\geq 41 \mathrm{~h}$ \\
$<10000$ Baht & $47(38-58)$ & $46(37-57)$ & $35(53-73)$ \\
$10001-20000$ Baht & $24(18-31)$ & $23(19-29)$ & $28(22-35)$ \\
$\geq 20001$ Baht & $15(10-23)$ & $23(18-30)$ & $\geq 41 \mathrm{~h}$ \\
Women & & & $27(23-32)$ \\
Monthly income & $<11 \mathrm{~h}$ & $11-40 \mathrm{~h}$ & $20(16-25)$ \\
$<10000$ Baht & $19(15-23)$ & $21(16-26)$ & $19(13-25)$ \\
$10001-20000$ Baht & $10(7-15)$ & $14(10-19)$ & $11(7-17)$ \\
$\geq 20001$ Baht & $16(10-24)$ & & \\
\hline
\end{tabular}

Darker shades correspond with higher workplace injury incidence. 
Table 4 Multiple logistic regression model of workplace injuries requiring medical care; the model is stratified by gender*

\begin{tabular}{|c|c|c|c|c|c|c|}
\hline & \multicolumn{3}{|c|}{ Women } & \multicolumn{3}{|c|}{ Men } \\
\hline & \multicolumn{2}{|c|}{$492 / 26858$} & \multirow[b]{2}{*}{ p Value } & \multicolumn{2}{|c|}{$746 / 22070$} & \multirow[b]{2}{*}{ p Value } \\
\hline & $\overline{\text { OR }}$ & $95 \% \mathrm{Cl}$ & & $\overline{\text { OR }}$ & $95 \% \mathrm{Cl}$ & \\
\hline \multicolumn{7}{|l|}{ Age (years) } \\
\hline$<30$ & 1 & Ref & \multirow[t]{4}{*}{0.07} & 1 & Ref & \multirow[t]{4}{*}{0.007} \\
\hline $30-39$ & 1.3 & 1.1 to -1.7 & & 1.1 & 0.9 to -1.4 & \\
\hline $40-49$ & 1.2 & 1.0 to -1.8 & & 0.9 & 0.7 to -1.1 & \\
\hline$\geq 50$ & 1.3 & 0.7 to -2.2 & & 0.6 & 0.4 to -0.9 & \\
\hline \multicolumn{7}{|l|}{ Marital status } \\
\hline First marriage & 0.6 & 0.5 to -0.8 & \multirow[t]{3}{*}{0.0005} & 1.0 & 0.8 to -1.2 & \multirow[t]{3}{*}{0.59} \\
\hline Never married & 1 & Ref & & 1 & Ref & \\
\hline Other & 0.8 & 0.6 to -1.1 & & 1.2 & 0.9 to -1.6 & \\
\hline \multicolumn{7}{|l|}{ Area } \\
\hline Rural & 0.9 & 0.8 to -1.1 & \multirow[t]{2}{*}{0.42} & 1.0 & 0.8 to -1.1 & \multirow[t]{2}{*}{0.85} \\
\hline Urban & 1 & Ref & & 1 & Ref & \\
\hline \multicolumn{7}{|c|}{ Weekly hours of paid work } \\
\hline$\leq 10$ & 0.8 & 0.6 to -1.1 & \multirow[t]{5}{*}{0.0002} & 0.9 & 0.7 to -1.1 & \multirow[t]{5}{*}{0.001} \\
\hline $11-39$ & 0.9 & 0.7 to -1.3 & & 0.9 & 0.7 to -1.2 & \\
\hline 40 & 1 & Ref & & 1 & Ref & \\
\hline $41-48$ & 1.2 & 0.9 to -1.6 & & 1.2 & 0.9 to -1.5 & \\
\hline$\geq 49$ & 1.4 & 1.1 to -1.9 & & 1.3 & 1.0 to -1.6 & \\
\hline \multicolumn{7}{|c|}{ Monthly personal income (Baht) } \\
\hline$\leq 7000$ & 2.0 & 1.5 to -2.6 & \multirow[t]{5}{*}{$<0.0001$} & 2.5 & 2.0 to -3.1 & \multirow[t]{5}{*}{$<0.0001$} \\
\hline $7001-10000$ & 1.4 & 1.1 to -1.8 & & 1.6 & 1.3 to -1.9 & \\
\hline $10001-20000$ & 1 & Ref & & 1 & Ref & \\
\hline $20001-30000$ & 1.0 & 0.7 to -1.3 & & 1.0 & 0.8 to -1.2 & \\
\hline$\geq 30001$ & 1.1 & 0.8 to -1.7 & & 0.8 & 0.6 to -1.0 & \\
\hline \multicolumn{7}{|l|}{ Self-employment } \\
\hline Yes & 1.1 & 0.8 to -1.4 & \multirow[t]{2}{*}{0.52} & 1.4 & 1.2 to -1.7 & \multirow[t]{2}{*}{0.0003} \\
\hline No & 1 & Ref & & 1 & Ref & \\
\hline \multicolumn{7}{|l|}{ Alcohol } \\
\hline None & 1 & Ref & \multirow[t]{3}{*}{0.35} & 1 & Ref & \multirow[t]{3}{*}{0.002} \\
\hline 1-5/week & 1.0 & 0.7 to -1.4 & & 1.3 & 1.1 to -1.6 & \\
\hline 6 or more/week & 1.4 & 0.9 to -2.4 & & 1.3 & 1.1 to -1.5 & \\
\hline
\end{tabular}

\section{DISCUSSION}

Among TCS participants, workplace injury resulting in medical care was common, particularly among men. Those working more than $48 \mathrm{~h}$ /week and working for a low income, and particularly self-employed workers working for a low income, were at increased risk. Study participants working $\geq 10 \mathrm{~h} /$ week were at increased injury risk per hour worked, but their injury risk per workeryear was reduced compared with full-time workers.

The strengths of this study are its large sample size and distribution of participants across Thai regions, urban and rural areas, occupations, formal and informal work and wage levels. Informal work was partially captured by distinguishing self-employed workers from other workers. Potential injury reporting bias related to health service access, that is, under reporting of serious injuries because of limitations in health service access, were addressed by repeating the analysis for all reported injuries, regardless of seeking medical attention. A study limitation was the self-report nature of the data, which relies on accurate recall and reporting. This was a crosssectional analysis. Not only was the data accuracy dependent on recall of exposure and injury, but it was assumed that exposure lead to injury and not vice-versa. Potentially, factors such as working hours, income and alcohol use may have been modified as a result of the injury. Although it seems unlikely that working hours would be increased as a result of an injury, workplace injury may have affected income and alcohol intake. Causality in the association between these factors and workplace injury cannot be established in this study.

Occupational injury incidence studies are limited in their generalisability by the methodology used and the study sample: TCS participants are undergoing longdistance education and they are a little younger and better educated than the Thai population. Really poor and uneducated workers are not in the cohort, and this may be reflected in the occupational injury rates. As injury rates were high in the low-income group, the workplace injury rate in the Thai population is therefore likely to be greater than that of TCS participants. This should be taken into account when comparing the overall annual incidence of workplace injuries reported in this study with national statistics reported in other studies. 
Comparison of incidence across studies becomes more complex when study methodologies differ. For example, workplace injury rates reported in this study were considerably higher than those reported in a study of non-fatal occupational injuries in employees in Malaysia: 34 and 18 injuries/1000 worker-years for men and women, respectively, in the TCS participants, compared with 10.7 and 3.6 reported for Malaysia, respectively. ${ }^{13}$ In the study by Abas et al, Social Security Organisation claims for workplace injury and diseases were analysed. Arguably not every occupational injury for which help was sought will result in a benefit claim, and Abas et al are therefore analysing a more severe workplace injury selection. Emergency department visits for occupational afflictions are $60 \%$ greater than the rate of accepted lost-time compensation claims, according to a Canadian study comparing incidence determined from emergency department visits to incidence determined from workers' compensation claims. ${ }^{14}$ In another example, a study conducted in a commune in Vietnam that is transitioning from agriculture to new industries, occupational injury incidence was reported based on face-to-face household surveys. ${ }^{15} 16$ The reported rates were more than 30 -fold the findings for the TCS, with an annualised incidence rate of $1001 / 1000$ full time employee equivalents. Although this may reflect a discrepancy in injury rates in the Thai and Vietnamese populations, the results also highlight the difficulties in occupational injury comparisons between countries.

In developing and newly industrialised countries, surveys provide an alternative to workers' compensation claims analysis for deriving injury rates, but the results are highly dependent on the study sample (eg, an agricultural commune compared with a nation-wide sample of working long-distance Open University students). Results also reflect the wording and translation of the survey and other methodological choices such as whether to include injuries arising from unpaid work, self-employment and work in the family business. The present study demonstrates the association between individual determinants and workplace injury; it is not the purpose of this study to present overall Thai occupational injury rates suitable for comparison to other national statistics.

Working more than $48 \mathrm{~h}$ /week and working for low wages were independent risk factors for workplace injury in the TCS participants. A US survey-based study has reported a similar trend; however, this was observed in women but not in men, ${ }^{17}$ possibly due to the higher burden of household activities for women and decreased time for rest and recovery. Other US survey-based studies have shown a similar correlation between increased working hours and work-related injury; results were not shown separately for men and women. ${ }^{5}{ }^{18}$ Decreased selfreported sleep was also found to be correlated with increased injury. ${ }^{5}$ A US study among workers in manufacturing showed that long hours of work increase the risk for an injury in a dose-response manner, and the case cross-over study design contributed to the evidence for a causal relationship between working hours and injury. ${ }^{4}$ In the present study the association between working hours and injury rates was confirmed for the Thai study participants. Interestingly, this trend was not seen when the injury incidence was expressed per $10^{6}$ hours worked. If the injury incidence associated with overwork exceeds that expected based on increased 'expose duration', ${ }^{18}$ one would expect the incidence per hours worked to increase with $>40$ working hours/week; however, this was not the case. Working less than $40 \mathrm{~h}$, however, and in particular working $10 \mathrm{~h}$ or less was associated with the greatest injury risk per hour worked. This may be due to relative job inexperience.

Thailand has recently introduced a minimum wage of $300 \mathrm{Baht} /$ day for all employees. Although the current study cannot establish causality in the relationship between income and workplace injury (and the minimum wage of $300 \mathrm{Baht} /$ day is still in the lowest income category of $<7000$ Baht as categorised in this study), the introduction of the minimum wage may reduce need to work multiple jobs. This could lead to a decrease in the number of workers working more than $48 \mathrm{~h} /$ week, which is likely to directly reduce the incidence of workplace injury.

Occupational injury incidence varied by gender and age in our study. Injury rates in previous studies are mostly reported to be greatest around the ages 20-25, and to decline with increasing age. ${ }^{19-21}$ In a Canadian study, the types of jobs of young workers were found to play an important role in the high injury risk: adjusting for job characteristics substantially reduced the increased injury risk of young workers. ${ }^{22}$ In other words, not youth itself but the jobs and work circumstances of youth contribute to the risk of injury. The peak injury incidence at age 30-39 among Thai workers, therefore, might partly be explained by the continued participation in heavy physical work and high risk jobs by Thai workers ( particularly by men), beyond the age of 25 .

Self-employed workers, representing a substantial proportion of the informal workforce, were at increased risk of injury. Unionisation rates in the informal workforce are generally low, and informal workers are not protected by existing workplace laws and regulations. ${ }^{23}$ Improvement of wages, working hours and workplace safety for these workers may require a gradual transition to formalised employment, and more wide-spread formation of labour unions.

In conclusion, among Thai workers represented in the TCS, occupational injury incidence was greater for men than for women and injury rates peaked at ages 30-39. Injury rates were increased among the self-employed, suggesting that statistics based on the formal workforce only may underestimate the injury rates in the combined (formal and informal) working population. The highest injury rates were recorded for those working more than $48 \mathrm{~h} /$ week and for low wage earners; this did not appear to exceed the risk expected from increased exposure. Overall reductions in occupational injury rates might therefore be achieved by limiting working hours to 
48/week, particularly among low-wage earners. The population of Thailand is growing, as is the Thai working population, including low wage earners and those with longer workdays. Particularly for these groups, there is an increasing need for effective injury preventive programmes.

Collaborators Thai Cohort Study Team: Thailand: Jaruwan Chokhanapitak, Chaiyun Churewong, Suttanit Hounthasarn, Suwanee Khamman, Daoruang Pandee, Suttinan Pangsap, Tippawan Prapamontol, Janya Puengson, Yodyiam Sangrattanakul, Sam-ang Seubsman, Boonchai Somboonsook, Nintita Sripaiboonkij, Pathumvadee Somsamai, Duangkae Vilainerun, Wanee Wimonwattanaphan. Australia: Chris Bain, Emily Banks, Cathy Banwell, Bruce Caldwell, Gordon Carmichael, Tarie Dellora, Jane Dixon, Sharon Friel, David Harley, Matthew Kelly, Tord Kjellstrom, Lynette Lim, Roderick McClure, Anthony McMichael, Tanya Mark, Adrian Sleigh, Lyndall Strazdins, Vasoontara Yiengprugsawan.

Contributors JB-G and RM analysed the data and conceptualised and drafted the manuscript. BT provided background information on the Thai labour force. SS and AS designed and instituted the Thai Health-Risk Transition research project and helped the data analysis and interpretation for this report. All authors read and approved the final manuscript.

Funding The Thai Cohort Study is funded by the International Collaborative Research Grants Scheme with joint grants from the Wellcome Trust UK (GR071587MA) and the Australian National Health and Medical Research Council (NHMRC) (268055), and as a global health grant from the NHMRC (585426).

Competing interests None.

Ethics approval Ethics approval was obtained from Sukhothai Thammathirat Open University Research and Development Institute (protocol 0522/10) and the Australian National University Human Research Ethics Committee (protocols 2004344 and 2009570). Informed written consent was obtained from all participants.

Provenance and peer review Not commissioned; externally peer reviewed.

Data sharing statement Data are available through a data access agreement which includes guarantees regarding ethical conduct and scientific quality of any proposed analyses and publications. Anyone wanting access should contact Adrian Sleigh or Sam-ang Seubsman (study Principal Investigators).

Open Access This is an Open Access article distributed in accordance with the Creative Commons Attribution Non Commercial (CC BY-NC 3.0) license, which permits others to distribute, remix, adapt, build upon this work noncommercially, and license their derivative works on different terms, provided the original work is properly cited and the use is non-commercial. See: http:// creativecommons.org/licenses/by-nc/3.0/

\section{REFERENCES}

1. Sleigh AC, Seubsman SA, Bain C. Cohort profile: The Thai Cohort of 87,134 Open University students. Int J Epidemiol 2008;37:266-72.
2. Siriruttanapruk S, Anantagulnathi P. Occupational health and safety situation and research priority in Thailand. Ind Health 2004;42: 135-40.

3. Siriruttanapruk Sat. Integrating occupational health services into public health systems: a model developed with Thailand's primary care units. Bankok: Office IL, 2006.

4. Vegso S, Cantley L, Slade M, et al. Extended work hours and risk of acute occupational injury: a case-crossover study of workers in manufacturing. Am J Ind Med 2007;50:597-603.

5. Lombardi DA, Folkard S, Willetts JL, et al. Daily sleep, weekly working hours, and risk of work-related injury: US National Health Interview Survey (2004-2008). Chronobiol Int 2010;27:1013-30.

6. Tadesse T, Kumie A. Prevalence and factors affecting work-related injury among workers engaged in Small and Medium-Scale Industries in Gondar wereda, north Gondar zone, Amhara Regional State, Ethiopia. Ethiop J Health Dev 2007;21:25-34.

7. Institute for Population and Social Research MU. Thai Health 12 Health Indicators of Thailand's Workforce, 2010.

8. Thailand Health Profile 2008-2010 Preparation Committee. Thailand Health Profile 2008-2010. Country Annual Health Reports, 2010.

9. Seubsman SA, Lim LL, Banwell C, et al. Socioeconomic status, sex, and obesity in a large national cohort of 15-87-year-old open university students in Thailand. J Epidemiol 2010;20:13-20.

10. Seubsman SA, Yiengprugsawan V, Sleigh A. A large national Thai Cohort Study of the Health-Risk Transition based on Sukhothai Thammathirat Open University students. ASEAN J Open Distance Learn 2012;4(1).

11. International Labour Organization. Women and men in the informal economy: a statistical picture. Geneva: International Labour Office, 2002.

12. Altman DG, Machin D, Bryant TN, Gardner MJ, eds. Statistics with confidence. 2nd edn. Bristol: BMJ Books, 2000.

13. Abas AB, Said AR, Mohammed MA, et al. Non-fatal occupational injuries among non-governmental employees in Malaysia. Int $J$ Occup Environ Health 2011;17:38-48.

14. Mustard CA, Chambers A, McLeod C, et al. Comparison of data sources for the surveillance of work injury. Occup Environ Med 2012;69:317-24.

15. Marucci-Wellman H, Leamon TB, Binh TT, et al. The work-related burden of injury in a rapidly industrialising commune in Viet Nam. Occup Environ Med 2010;67:244-50.

16. Marucci-Wellman $\mathrm{H}$, Leamon TB, Willetts $\mathrm{JL}$, et al. Occupational injuries in a commune in rural Vietnam transitioning from agriculture to new industries. Am J Public Health 2011;101:854-60.

17. Wirtz A, Lombardi DA, Willetts JL, et al. Gender differences in the effect of weekly working hours on occupational injury risk in the United States working population. Scand J Work Environ Health 2012;38:349-57.

18. Dembe AE, Erickson JB, Delbos RG, et al. The impact of overtime and long work hours on occupational injuries and illnesses: new evidence from the United States. Occup Environ Med 2005;62:588-97.

19. Breslin FC, Smith P. Trial by fire: a multivariate examination of the relation between job tenure and work injuries. Occup Environ Med 2006:63:27-32.

20. Breslin FC, Smith PM, Moore I. Examining the decline in lost-time claim rates across age groups in Ontario between 1991 and 2007. Occup Environ Med 2011;68:813-17.

21. Gluck JV, Oleinick A. Claim rates of compensable back injuries by age, gender, occupation, and industry. Do they relate to return-to-work experience? Spine (Phila Pa 1976) 1998;23:1572-87.

22. Breslin FC, Smith P. Age-related differences in work injuries: a multivariate, population-based study. Am J Ind Med 2005:48:50-6.

23. Kelly M, Strazdins L, Dellora T, et al. Thailand's work and health transition. Int Labour Rev 2010;149:373-86. 